\title{
As representações sociais da violência doméstica: uma abordagem preventiva ${ }^{\star}$
}

\author{
Social representations of physically abused \\ adolescents in violent homes: an preventive approach
}

Maria da Conceição N. Monteiro 1

Mara Aparecida Alves Cabral 2

Denise Jodelet 3

\footnotetext{
* Esta pesquisa recebeu apoio financeiro do $\mathrm{CNPq} /$ Capes.

1 Centro Latino-Americano de Estudos da Violência e Saúde "Jorge Careli", Fundação Oswaldo Cruz, Av. Brasil 4036, sala 702, 21040-361 Rio de Janeiro, RJ, Brasil.

mcnm@ensp.fiocruz.br 2 Faculdade de Ciências Médicas, Universidade Estadual de Campinas.

3 Laboratório de Psicologia Social, École des Hautes Études en Sciences Sociales, Paris, França.
}

\begin{abstract}
This study aims to identify the construction of three types of social representations pertaining to domestic violence: the violence itself, the aggressors, and adolescent victims of violence as seen by themselves. The study interviewed 90 adolescents in the city of Campinas, São Paulo, in order to identify underlying themes to base a proposal for prevention of domestic violence in that city. The point of departure was an analysis of the issues surrounding the domestic violence phenomenon and its relation to socially inadequate behaviors (rebelliousness and marginal or violent conduct) and their effect on adolescents' self-image. The data-gathering methodology included an initial interview and questionnaires and records from the Regional Center on Child Abuse (CRAMI) to identify reports of physical violence during childhood and to investigate the discourses employed by the various social actors, taking a dialogical perspective as the main source of information and oral and written expression. The analysis was both qualitative and quantitative. The qualitative approach focused on discourse content from a semantic and lexical perspective. The quantitative approach used a factor correspondence analysis aimed at identifying the core social representations of domestic violence in the two groups of adolescents (the study and comparison groups).
\end{abstract}

Key words Social Representations; Adolescence; Domestic Violence
Resumo Este trabalho tem como objetivo identificar a construção de três tipos de representações sociais: as da violência doméstica, as dos agressores e as que os adolescentes, agredidos na infância têm de si mesmos. Buscaram-se temas que norteassem uma proposta de prevenção da violência doméstica pesquisando-os em 90 adolescentes da cidade de Campinas, São Paulo. O ponto de partida foi analisar a problemática que envolve o fenômeno da violência doméstica e sua relação com os comportamentos socialmente inadequados (rebeldia, condutas marginais ou violentas) e seu efeito na auto-imagem dos adolescentes. A dinâmica de coleta de dados visou, através da entrevista inicial, dos questionários e das fichas de registro do Crami-Centro Regional de Registro e Atenção aos Maus Tratos na Infância, Campinas - a identificar a notificação de violências físicas sofridas na infância e a investigar os discursos dos atores sociais, numa perspectiva dialógica, como a principal fonte de informação e expressão oral e escrita. A análise realizada foi de natureza qualitativa-quantitativa. A primeira, destina-se ao exame dos conteúdos dos discursos, através da análise semântica e léxica. A segunda referese à análise fatorial de correspondência, que se destina a identificar os núcleos centrais das representações sociais da violência doméstica nos dois grupos de adolescentes.

Palavras-chave Representações Sociais; Adolescência; Violência Doméstica 


\section{Introdução}

A relação pessoal com o tema da violência doméstica surgiu durante $o$ atendimento às crianças vitimadas, notificadas no Centro Regional de Registro e Atenção aos Maus Tratos na Infância (Crami) e atendidas nos hospitais e prontos-socorros da cidade de Campinas, São Paulo, no período de 1990/1991.

No primeiro atendimento as crianças expressavam sentimentos de medo, retraimento, submissão, inferioridade, apatia, revolta e vergonha. Sentimentos, esses, significativos de suas vivências psicossociais e também presentes nos relatos dos agressores (pais ou responsáveis). Após o atendimento médico e hospitalar essas crianças retornavam para seus lares sem nenhuma forma de assistência ou acompanhamento psicológico.

Quatro anos depois, em visitas domiciliares, retornamos para entrevistar essas crianças, que se encontravam vivendo o processo de adolescer. Nem crianças nem adultos pareciam saber que caminhavam para um futuro, acompanhadas de exigências sociais quanto à sua tomada de consciência e atuação na sociedade. Em seus relatos observamos muitos comportamentos, atitudes e opiniões agressivas ou violentas, desenvolvidas no contexto de suas relações familiares e sociais. Eram condutas freqüentemente caracterizadas por práticas anti-sociais e delinqüentes.

A convivência com esses jovens e suas famílias conflituosas possibilitava diferentes abordagens de pesquisa, nas áreas de cultura, educação e saúde, visando à assistência e práticas preventivas.

Realizamos um trabalho descritivo e comparativo onde a conexão com as demais disciplinas permitiu a construção do objeto de pesquisa que se revelou através do discurso dos jovens. Ressaltamos a importância dos dados empíricos e os relatados pela literatura sobre as estatísticas de morbidade e mortalidade causadas pela violência doméstica. Consideramos o número de casos de violência silenciosa ou não notificadas, essas, devido ao medo do informante ser identificado. Observamos a não notificação dos hospitais particulares e a falta de mobilização da sociedade quanto às violências domésticas ou familiares, por considerá-las problemas que ocorrem em espaços privados.

A construção teórica desta pesquisa enfoca o conceito de representações sociais, en- quanto um "produto dinâmico da atividade mental" (Jodelet, 1994), que possibilita a emergência de sinais e significados psicossociais, pertinentes à vida cotidiana e à realidade social, elaborados através do mundo das idéias e da modalidade de pensamento de cada adolescente.

Procuramos salientar entre as representações da violência doméstica, a "função de orientação" (Moscovici, 1976), que permite ao adolescente agir, de acordo com suas representações sociais, que podem orientar seus comportamentos e suas práticas.

Entendemos as representações sociais como formas de pensamento utilizadas na comunicação, na compreensão e no ensino do meio social, material e ideativo, que surgem das observações dos atores sociais (sujeito) e de seus relatos de fatos e fenômenos sociais (objeto) ocorridos. A construção das representações sociais inclui, também, as estruturas imaginárias e simbólicas dos adolescentes. Nesta pesquisa, esperamos que eles não registrassem somente suas opiniões, atitudes, imagens e experiências a respeito da violência doméstica ocorrida na infância, mas que fossem capazes de imaginar e de expressar o simbólico em suas representações sociais, e que em suas práticas de vida pudessem dar um sentido ao mundo em que vivem (Jodelet, 1994).

As representações sociais da violência doméstica referem-se à "construção sócio-cognitiva" (Abric, 1994) ou seja, enfatizamos o conteúdo e o processo de pensamento, a compreensão dos adolescentes em relação a este fenômeno social e a repercussão no contexto que eles estão inseridos e são evidenciados.

\section{Metodologia}

Os procedimentos metodológicos utilizados na coleta e análise das representações sociais, privilegiaram o conteúdo do discurso pesquisado na entrevista inicial e os eixos temáticos pré-estabelecidos nos instrumentos de pesquisa. Identificamos as categorias centrais retiradas da linguagem oral e escrita. Elas constituem as representações sociais da violência doméstica para os adolescentes do grupo de estudo (vitimados) e do grupo comparativo (nãovitimados).

As observações referem-se às reações que os adolescentes apresentaram no momento da entrevista inicial e ao responderem aos instru- 
mentos de pesquisa. A pesquisadora registrou outras reações ou acontecimentos significativos, ocorridos durante a visita domiciliar.

Foram estudados 90 adolescentes de ambos os sexos, com idades compreendidas entre 12 e 18 anos, que expressaram seu desejo de participar. Para atingir nossos objetivos foram pesquisados adolescentes representativos da população alvo. Entendemos por população alvo aquela constituída por adolescentes com história de violência doméstica, do tipo física, durante a infância. Por tratar-se de uma população homogênea quanto à idade, escolaridade e condições sócio-econômicas, consideramos o índice de $20 \%$, das 256 ocorrências notificadas, representativo desta população, o que resultou na estimativa de aproximadamente 60 sujeitos para compor o grupo de estudo (Santos, 1987).

Os 90 adolescentes responderam aos instrumentos de pesquisa em situações específicas: Crami-Casa; Escolas-Escola; Vizinhos-Casa, no período de junho/1996 a março/1997.

Para os adolescentes que responderam em casa, a aplicação foi individual. A aplicação coletiva aconteceu nas escolas, em salas de aula. O tempo de duração para a entrevista inicial e para a aplicação dos instrumentos de pesquisa foi em média de duas horas.

Salientamos que, ao término da coleta dos dados, a pesquisadora concluiu que o discurso era constituído de um conjunto de opiniões, impressões, atitudes, crenças e ideologias; que as informações precisavam ser ordenadas, organizadas, analisadas e interpretadas; que a utilização dos questionário mostrou dados e fatores explicativos da população alvo; que os instrumentos de pesquisa abrangeram conteúdos qualitativos e quantitativos; que as questões formuladas foram distribuídas, conforme suas especificidades, entre perguntas abertas e fechadas. A pesquisadora ficou convicta da importância do método de análise qualitativo-quantitativo, tendo como referência a avaliação e análise do projeto piloto.

Dessa forma, a análise qualitativa foi realizada através da dimensão semântica e léxica (Bardin, 1988). Criamos categorias que constituíram-se de: 1) traços psicológicos; 2) relações sociais; 3 ) relações familiares; 4) atributos físicos; 5) temas valorizados ou rejeitados no discurso; 6) contradições e sutilezas; 7) palavras-chave representadas por sinônimos ou vocábulos afins; 8 ) sentimentos e atributos (positivos ou negativos) presentes nas repre- sentações de si mesmos, nas representações sociais do agressor e na violência doméstica contra crianças.

$\mathrm{Na}$ análise quantitativa os dados provenientes das questões fechadas e abertas foram tratados pelo programa Epi Info 6. Para isto, foi preparado um banco de dados com todas as questões dos instrumentos de pesquisa. As respostas às questões abertas também foram incluídas nesse banco, após todos os procedimentos da análise qualitativa. Para elas, definimos categorias, temas valorizados e rejeitados e palavras-chave. O tratamento estatístico permitiu a comparação dos grupos, o cruzamento das variáveis, as freqüências e associações e, finalmente, a elaboração de tabelas e gráficos. A análise fatorial de correspondência teve como interesse principal identificar o núcleo central da representação social da violência familiar ou doméstica, através da técnica de associação livre. Esta técnica permitiu aos adolescentes escreverem as dez primeiras palavras que lhes viessem à mente, a partir de uma expressão indutora. A aplicação da análise fatorial de correspondência, como um teste de correlação de dados, teve como objetivo verificar quais palavras estavam mais próximas dessa expressão e se os vocábulos revelavam-se diferentemente entre os dois grupos de interesse, ou seja, o quanto cada vocábulo tinha $\chi^{2}$ estatisticamente associado a expressão indutora, considerando-se a posição da palavra evocada e em qual grupo ela se encontrava. Após a análise, selecionamos somente as palavras que apresentaram contribuição relativa para formar o eixo de 0,51389 (100\% da inércia). Os recursos matemáticos e estatísticos, pertinentes ao método quantitativo, validaram os resultados das análises de conteúdo qualitativo, relativos ao agrupamento e à classificação das categorias e dos temas identificados nas questões dos instrumentos de pesquisa.

\section{Resultados}

Nas representações que os adolescentes têm de si mesmos, verificamos, em 18,3\% do grupo de estudo, um discurso permeado de sentimentos de ansiedade e medo em relação às condutas anti-sociais, como fugir de casa, roubar e usar drogas: "quando eu tinha dez anos, minha mãe me botou de castigo de noite, ajoelhada na calçada, de baixo de chuva. Outra vez cortou os meus punhos dizendo que eu rouba- 
va. Quando eu olho prá minha mãe, eu sinto um mal-estar, eu fico doente. Eu sofro calada; eu me defendo saindo de casa".

Os atributos físicos, evidenciados pelos adolescentes com vivência de maus-tratos na infância, são referidos por 8,3\%, que consideram seu corpo como um tema valorizado na análise do conteúdo. Salientamos que a imagem corporal, na adolescência, vai lhe servir de apoio, de objeto de admiração e vaidade, representando um atributo de boa auto-estima; $8,3 \%$ foi um resultado que indica a necessidade de novos estudos sobre a representação do corpo entre os adolescentes vitimados na infância.

Os atributos simbólicos, expressos pelos adolescentes em relação às categorias mais valorizadas, referem-se aos sentimentos de esperança. Desses, 33,3\% referem-se a um projeto de vida (desejo de retornar a estudar e sucesso no trabalho). Todavia, na análise das palavras-chave, a capacidade e o interesse pelo trabalho mereceram maior destaque, comparativamente ao sucesso escolar.

Os relacionamentos familiares e sociais são tímidos, com temas valorizados (gentileza/educação) em 20\% nos adolescentes deste grupo, nos quais estão presentes as exigências sociais e o sistema de valores internalizados pela família. Os temas rejeitados (timidez/submissão), mostraram ser possível em $43,3 \%$ a presença de conflitos intrapsíquicos nessas formas de relacionamentos.

Os traços psicológicos e relações sociais (alegria/comunicação) identificados entre os adolescentes vitimados na infância, poderiam estar significando: imagem idealizada; elaboração da agressão; e mecanismo de negação da violência doméstica sofrida.

A capacidade de sonhar foi expressa por $33,3 \%$ do grupo de estudo, ou seja, um terço desta amostra demonstrou sentimentos de esperança no futuro. Este resultado pareceu-nos pouco significativo, à medida em que $66,7 \%$ do grupo de estudo não valorizaram esse tema que, para Davitz e Davitz (1992), está relacionado à fantasia do adolescente - o mecanismo pelo qual ele planifica seu futuro, seus ideais profissionais e pessoais.

Neste grupo, $40 \%$ dos adolescentes referem-se a sentimentos de desvalorização (baixa auto-estima) e características pessoais destrutivas (condutas anti-sociais e violentas), como reflexos da vivência de maus-tratos físicos na infância e identificação com o agressor.
Outros traços psicológicos, expressos através de categorias rejeitadas (sentimentos de insatisfação, medo, apatia, tristeza, retraimento, ansiedade, submissão e agressão), já foram relatados no perfil das crianças e adolescentes vitimados (Haskett, 1990).

$\mathrm{Na}$ análise qualitativa das entrevistas, os sentimentos de rejeição e desaprovação verificados em 11,6\% dos adolescentes deste grupo poderiam estar impulsionando condutas anti-sociais, tais como: fugas de casa, roubose comportamentos delinqüentes, associados ao uso combinado de álcool e drogas. Estes resultados revelam a fragilidade dos jovens diante das drogas, da força e da sedução do álcool, que lhes permite "uma onda", que os deixa diferentes, talvez "outras pessoas", mais alegres, descontraídas e corajosas. Para aqueles que freqüentam os "sons de rua", as drogas lícitas e ilícitas são acessíveis, "embalando" as noites de Campinas. Assim, os jovem que as usam reproduzem os comportamentos de outros adolescentes, de países ocidentais.

Os relacionamentos sociais conflituosos, associados à histórias de maus-tratos na infância, foram estatisticamente significativos $\left(\chi^{2}-0,05\right)$, sugerindo que $96,7 \%$ dos adolescentes têm dificuldades em lidar com um mínimo de conflito social. Eles reagem agressivamente, evitando o diálogo e a solidariedade entre seus pares, precipitando agressões físicas contra colegas da mesma idade

No grupo comparativo, $50 \%$ revelam traços psicológicos de boa auto-estima e relacionamento social e familiar positivos.

A referência ao corpo, como objeto de valorização, foi verificada em $16 \%$, embora, em $33,3 \%$, as representações de si mesmos constituem-se de temas rejeitados, na imagem pessoal, quando esta se contrastava com o ideal de beleza cultuado pela sociedade. As representações de si mesmos enfocam valores impostos pela sociedade através da mídia, que veicula como a figura ideal: jovem bonito, livre, forte, porém, magro. Tal como no grupo de estudo, os atributos físicos rejeitados, referem-se também ao corpo associado às primeiras transformações físicas do início da puberdade, aos conflitos intrapsíquicos da perda do corpo da infância e surgimento de um corpo que se modifica, possibilitando a "crise normal" da adolescência (Aberastury \& Knobel, 1981).

As representações de si mesmos revelamse através de valores e caracteres positivos e negativos que descrevem a imagem pessoal e 
a imagem social dos adolescentes. Em níveis quantitativos, a imagem pessoal foi expressa por valores positivos, os quais, no grupo de estudo, foram menos freqüentes em relação ao grupo comparativo, principalmente entre os adolescentes notificados no Crami/Campinas. A imagem social dos adolescentes, com vivência de violência na infância, revela gentileza, timidez e trabalho, contrariamente, ao grupo comparativo que elegeu sete atributos positivos para descreverem sua imagem social: sonhador, calmo, gentil, alegre, atencioso, simpático e trabalhador.

$\mathrm{O}$ afeto depressivo e a timidez foram identificados em 32\% do total da amostra do grupo de estudo. Este perfil psicológico foi expresso através de condutas de medo, retraimento $e$ isolamento, associadas às dificuldades do processo de socialização, em relação ao grupo comparativo que se mostrou mais espontâneo e menos controlado. Este afeto foi manifestado pela tristeza, solidão e choro, que podem estar associados à privação afetiva na infância. A imagem física, para os adolescentes do grupo de estudo (34\%) e para os adolescentes do grupo comparativo (27\%), destaca o corpo como um atributo negativo expresso através de críticas, descontentamentos e insatisfações em relação à imagem de si mesmo.

O corpo como uma categoria valorizada foi identificado em $20 \%$ dos adolescentes do grupo comparativo contra $10 \%$ do grupo de estudo. De um modo geral, o grupo de estudo descreveu-se mais negativamente em relação ao grupo comparativo.

As representações sociais dos agressores no grupo de estudo expressam-se por meio de um discurso ambivalente, oscilando entre os sentimentos de raiva, medo, piedade, tristeza e desejo de ajudar os agressores que, em 74\%, eram os seus pais.

Os adolescentes, ao relatarem as representações sociais dos agressores, nem sempre o fizeram com tranqüilidade; havia o silêncio, as reticências e, principalmente, o medo e a vergonha de revelarem que experiência com pais agressores faz parte de suas histórias de vida. Em 65\%, os discursos apresentaram conteúdo ambivalente: "é uma maldade agredir os filhos, mas, em relação ao meu pai, eu gosto dele, eu me orgulho de meu pai, eu gosto dele"; em $35 \%$ apresentaram conteúdos constituídos de atos e sentimentos de crueldade: "meu pai cortou minha perna com a faca da cozinha"; "eles usam revólveres, facas, e paus"; "meu pai, nu- ma noite de inverno, nos pôs para dormir numa construção ao lado de nossa casa".

Neste trabalho, as representações sociais dos agressores revelam aspectos psicopatológicos e problemas emocionais graves, da mesma forma que o modelo multidimencional descrito por Gelles (1973) destaca os aspectos sócio-culturais, o status sócio-econômico, as experiências prévias com a violência e enfatiza a necessidade de um exame minucioso do contexto psicossocial dos familiares violentos.

Os 60 adolescentes do grupo de estudo consideraram que as atitudes agressivas contra as crianças e os adolescentes são tomadas em $42 \%$, pelos pais, em $32 \%$, pelas mães; em $26 \%$ os agressores são irmãos, avós, padrastos ou outros parentes.

As representações do grupo de estudo traduzem o processo de identificação com o agressor e permitem a reprodução da agressão: "acho que todos sentem ódio e rancor das lembranças das brigas, mas eu sou esperto e querido nas ruas pelos outros; fui lider de grupos de adolescentes, tinha meu horário no Taquaral (para assaltar as pessoas) mas não chamava ninguém para participar. Quando alguém queria entrar no grupo, devia me obedecer. Prefiro lidar com camaradas inteligentes, que me ouvem e não agem precipitadamente".

Os acontecimentos de violência são freqüentemente veiculados pela mídia. A revista Veja (1997) publicou reportagem sobre adolescentes de classe média que colocaram fogo num índio que dormia numa parada de ônibus, em Brasília. Atos como este podem estar expressando as relações conflituosas de "poder" dentro da família, ou significando a ponta de um iceberg que denuncia a ausência de proteção sócio-familiar ou a negligência dos papéis atribuídos aos dirigentes do Estado e aos pais de família.

Este trabalho, com 90 adolescentes, sobre a representação do agressor é preocupante, se considerarmos que, em um espaço de reflexão singular, em 98,6\% dos adolescentes, houve uma necessidade de falar de justiça, sentimentos de ódio, vingança, medo e indignação. Estes sentimentos, além de fazerem parte da estrutura das representações sociais dos agressores, expressam atitudes que estes adolescentes encontram para se proteger, defender ou reagir aos perigos deste fenômeno psicossocial. A expressão de sentimentos negativos ou a reprodução de condutas agressivas pelos adolescentes, em espaços públicos, são adequáveis à fun- 
ção do saber (Moscovici, 1976), como uma forma de conhecimento que permite compreender e explicar a realidade através da comunicação social, na vivência das relações com seus pais ou responsáveis. Nas representações sociais dos agressores, no grupo de estudo, nota-se o processo cognitivo expresso na reprodução da violência, mobilizado pelos sentimentos de revolta e indignação pela vivência dos maus-tratos: "acho que os pais agressores deveriam levar uma pisa de couro, como fazem com os filhos." "Ser preso". "Pedir perdão aos agredidos". "Ficar preso no mínimo cinco meses". "Levar uma multa e pagar em dinheiro". "Separar-se do filho para sofrer um dia". "Ser instruídas como devem educar e criar os filhos, e se isso não for suficiente, devem perder a guarda dos filhos, para outros parentes". "Quando ele maltratar os filhos deve levar um surra também". "Devem ficar na cadeia e não sair nunca mais". "Pagar com a mesma moeda". Estes sentimentos internalizados vão interagir em suas relações sociais e podem expressar uma tomada de posição (Moscovici, 1976) para o desenvolvimento de comportamentos agressivos e violentos contra seu grupo social e contra a sociedade de um modo geral. Ao identificar-se com o agressor, o adolescente poderá desenvolver a função da repetição freqüente, ou seja, é provável que ele reproduza episódios de agressão, manifestados até mesmo por uma situação de estresse. A identificação com o agressor protege-o contra os temores de aniquilamento e pela antecipação de uma recorrência. As crianças agredidas precisam repetir a situação da agressão, em uma tentativa de obter o controle e dividir o "poder" com o agressor, a partir de uma identificação com o mesmo, para neutralizar os sentimentos de inatividade e aniquilamento associados aos maus-tratos.

Neste estudo notamos a representação do agressor: $42 \%$ referem-se ao pai como o membro da família que pratica mais agressões contra os filhos. Os sentimentos ambivalentes em relação aos pais fazem parte do processo de construção das representações sociais que os adolescentes têm de seus agressores.

A reflexão sobre a imagem de um agressor, sendo parte de instituições sagradas e de modelo de identificação, expressa discursos que desculpabilizam os comportamentos agressivos dos pais contra os filhos. Todavia, o núcleo central, ou seja, a estrutura nuclear que se constitui pela freqüência de palavras (Aissami, 1990; Abric, 1994), em 98,6\% dos adoles- centes deste grupo, inclui elementos indicadores, sejam substantivos ou adjetivos, de desejos de justiça ou de vingança, seguidos de justificativas e desculpas das atitudes de seus agressores. Estes resultados requerem estudos mais aprofundados e especificamente direcionados à análise das funções geradoras ou organizadoras desses discursos.

Os adolescentes, sem história de maus-tratos físicos na infância, expressaram as representações sociais dos agressores, através de informações que receberam da mídia, de histórias infantis e de pessoas que passaram por essas situações. Este grupo revelou também, sentimentos de revolta, ódio e indignação pela imagem dos agressores. O grupo comparativo define o agressor com base em seu entendimento individual, constituído de elementos psicológicos, sociais e morais associados à idéia de maus-tratos contra crianças. Enquanto os adolescentes, que têm histórias de maustratos físicos na infância, expressaram sentimentos ambivalentes sobre seus agressores, aqueles não vitimados, na faixa etária entre 12 e 16 anos, mostraram, em seus relatos, opiniões e atitudes com grande intensidade de violência.

No decorrer da análise, identificamos a presença de um discurso contraditório no grupo comparativo, com conteúdo extremamente agressivo, não em relação à vivência de maus-tratos, mas direcionado ao agressor: "os agressores são pessoas ruins que não prestam". "Eles devem sofrer um acidente". "Ver a morte na cara deles, sem perdão". "Eles devem sofrer". "São pessoas monstruosas que bebem e xingam". "Devem ser amarrados e alguém dar uma surra de chicote bem grosso em praça pública e receber a prisão perpétua". "Precisam receber a mesma violência que eles fizeram no outro". "Ir para a prisão e morrer na cadeia de tanto remorso". "A punição deve ser ao nível de sua violência". "Devem morrer ou ficar isoladas". "Devem ir para a cadeira elétrica ou a cadeia".

Para este grupo, a representação do agressor, tal como as representações da violência doméstica, também é construída por elaborações que circulam no meio ambiente, pertencentes ao imaginário social, que proclama punições severas aos agressores. Um exemplo destas idéias e atitudes são os linchamentos públicos.

Nesta perspectiva, o agressor é visto como um fenômeno social cruel, que ocorre no interior desta sociedade e que, segundo os relatos 
desses adolescentes, merece punição severa porque ameaça a vida dos jovens e transgride a moral e a lei.

Nos adolescentes com idade acima de 16 anos, as representações sociais dos agressores expressam uma preocupação quanto à ausência de políticas públicas que efetivamente propiciem proteção social, psicológica e médica. No relato desses atores sociais, não foi enfatizada apenas a ação de denunciar, mas reivindicações de mudanças nas áreas de educação, saúde, trabalho, lazer e cultura como alternativas para recuperar os pais e os filhos vitimados. As representações sociais dos agressores não suscitam o desejo de retaliação, mas um sentimento de compaixão por aqueles que estão em sofrimento. Para eles, as atitudes e a imagem dos agressores estão comprometidas pela rede de causalidade psicossociológica, compreendida, nesta pesquisa, como decorrente de um determinado tipo de Estado, que favorece o desenvolvimento da violência doméstica, através da ausência de proteção e da repressão social. "Eles têm pouco dinheiro para a família". "Não têm trabalho". "Acho que eles devem ser tratados por uma psicóloga e, se não der certo, perder a guarda de seus filhos". "Eles estão doentes e precisam de ajuda". "São pessoas amargas, solitárias, desconfiadas, medrosas e tristes". "Pessoas que maltratam seus filhos devem receber assistência". "São pessoas fracas, ficam todas vermelhas e se sentem doentes... são pessoas agressivas, violentas e cheias de dúvidas". "São pessoas muito nervosas, você sente quando a pessoa é violenta".

As representações sociais da violência doméstica são constituídas por aspectos psicossociais, presentes neste fenômeno social. Identificamos, entre eles: o alcoolismo, a drogadição, o baixo nível de escolaridade dos pais, as precárias condições sócio-econômicas, a ausência de desejo pela maternidade e paternidade, associados aos conflitos psicológicos e às depressões que possibilitam negligência, abandono, abusos psicológicos; as psicopatologias, como a pedofilia, quando ocorrem abusos sexuais e estupros, direcionadas às crianças da família ou do agrupamento familiar.

No estudo das características psicossociais dos agressores, os pais revelaram seus conflitos vivenciados no cotidiano familiar. Em suas expressões, observamos desesperança, inquietação e insatisfação com a vida, em decorrência da impossibilidade de desenvolverem-se como indivíduos e cidadãos (Monteiro, 1992).
Nesta mesma ótica, quatro anos depois, os filhos e os enteados, num momento singular, expressaram suas representações sociais elaboradas a partir de efeitos nefastos que os conflitos dos pais exercem em suas vidas, seus significados e as condições psicossociais vividas na infância, sendo elas responsáveis por seus comportamentos na adolescência.

$\mathrm{Na}$ identificação do núcleo central, observamos que os dois grupos encontravam-se em oposição. O maior valor de contribuição relativa foi determinada pelo grupo comparativo, no vocábulo angústia - como uma sensação desagradável, independente da vivência traumática. O sentimento de angústia diante da "morte" foi o vocábulo, em toda a análise, que obteve o maior valor de contribuição relativa $(0,052791)$. Pareceu-nos que ele é intensamente sentido, como sensação muito desagradável, diante de uma ameaça que este grupo relatou como não vivenciada.

O vocábulo surra materializa o desconhecido, refletindo-se na realidade, ao aproximarse da expressão violência familiar. Os outros vocábulos, com altos índices de contribuição relativa, expressam poder constituído na família; aspectos psicológicos; solicitação da lei; e características sociais do contexto familiar (Tabela 1).

O Núcleo central da expressão violência familiar, a morte está representada, simbolicamente, com o maior valor de contribuição relativa $(0,052536)$. Considerando que nesta amostra $42 \%$ dos pais são os agressores e 35\% não têm contato com o pai, o vocábulo morte poderia estar expressando a perda ou a ausência paterna. Para Kovács (1991), a morte simbólica refere-se a perdas não-resultantes da morte física, mas às vivências de separação, ou às perdas afetivas. Dessa forma, a ausência paterna impede o contato real e afetivo tornando inexistente a relação pai-filho.

Tabela 1

\begin{tabular}{lc}
\hline Palavras & Contribuição relativa \\
\hline Angústia & 0,052791 \\
Surra & 0,045250 \\
Poder, casa, egoísmo & 0,037708 \\
Dor, prisão & 0,030166 \\
Agressão, favela, & 0,022625 \\
cocaína, crack & \\
\hline
\end{tabular}


A morte, poderia estar sendo sentida como uma perda irreversível, brusca, evocando sentimentos de tristeza, sofrimento e agressão, que também constituem o núcleo da expressão violência familiar no grupo de estudo (Tabela 2).

Em 83,3\%, as representações sociais da violência doméstica traduzem atos e comportamentos agressivos vivenciados por esta população, ou seja, os adolescentes expressaram aquilo que estava inscrito em suas histórias de vida. Não observamos somente a carência material como o componente principal de suas representações sociais. Muito mais que a pobreza material, percebemos a ausência das funções parentais na dinâmica familiar, dificultando o desenvolvimento adequado da responsabilidade e manutenção da prole, através de uma renda mensal ( $66 \%$ das famílias ganham menos de um a três salários mínimos) que lhes garanta condições de sobrevivência com dignidade.

$\mathrm{Na}$ fala desses adolescentes, a ausência dos pais foi traduzida pela falta de harmonia, serenidade, amor e carinho que, somente alguns, tiveram a oportunidade de vivenciar. Na análise do significado destas representações sociais, a falta acaba por atingir o mundo dos sentimentos e das emoções.

Observamos um discurso no qual as vítimas, pais e filhos, parecem inimigos, representantes dessa unidade social, em que os adolescentes expressam o seu ódio e revolta. Em meio a sentimentos de desesperança, os adolescentes revelam, em seus discursos, conflitos psicossociais e contradições entre o desejo pessoal e a realidade social, da qual fazem parte na posição de excluídos.

Certamente não existirão respostas para esses comportamentos, se não pensarmos na multicausalidade, presente neste fenômeno psicossocial e imbricada em suas representações sociais, construída através de condições de pobreza das famílias residentes em favelas e arredores de Campinas. Com isto, pretende-

Tabela 2

\begin{tabular}{lc}
\hline Palavras & Contribuição relativa \\
\hline Morte & 0,052536 \\
Tristeza & 0,037708 \\
Sofrimento & 0,027325 \\
Agressão & 0,022625
\end{tabular}

mos defender que é possível minimizar os maus-tratos contra os filhos, através de programas ligados à proteção social do Estado e, principalmente, por meio de estímulos eficazes nas áreas de educação, saúde e cultura.

Os adolescentes, através de seus gestos, falas e (ou) silêncio, parecem apreender o mundo e a realidade que os cerca, sem saber o que lhes espera no futuro, como indivíduos e cidadãos. As representações das violências praticadas por eles: assalto à mão armada, abuso sexual, agressão aos velhos, assassinatos em situações específicas (defesa pessoal ou estresse), foram consideradas leves e médias, atingindo a escala de $5 \%$ a $10 \%$ em freqüências isoladas no grupo de estudo.

As condutas anti-sociais, como fugir de ca$s a$, chutar portas, gritar e xingar os parentes $e$ amigos, lançar objetos nas pessoas atingiram as freqüências de $25 \%$ nos adolescentes deste mesmo grupo.

Desta forma, podemos considerar que a banalização da violência é, também, uma conseqüência de vê-la, diariamente, em casa, nas ruas e na mídia, fazendo parte do cotidiano das pessoas, quando todos podem participar dela, como agentes ou vítimas. São significados que demonstram não só o sadismo como uma necessidade de causar dor ao outro, mas, principalmente, o exercício do domínio dos adultos entre si e (ou) em direção à criança agredida. Nesta ênfase, o masoquismo, como a aceitação às situações de constrangimento $\mathrm{e}$ humilhação descritas pelos adolescentes em seus relatos, enfatiza os atributos rejeitados em sua auto-imagem, que devem merecer a reflexão dos gestores públicos no que concerne às políticas de saúde mental e de educação.

As representações sociais da violência doméstica estão qualitativamente relacionadas ao alcoolismo e drogadição, gerando problemas emocionais que podem desencadear comportamentos violentos no adolescente, independentemente de fatores genéticos ou biológicos mas, principalmente, ligados às influências ambientais e sociais.

Entendemos o caminho político como uma das alternativas expressa pelos adolescentes, uma possibilidade de minimizar os problemas da violência doméstica, através do cumprimento de providências previstas no Estatuto da Criança e do Adolescente e de ações de políticas públicas de proteção à família - meta prioritária para prevenir, ou se pensarmos de forma mais racional, para abolir os sentimen- 
tos de desesperança, abandono, privação e desproteção, simbolizados pela cronificação da violência doméstica. Essas representações $(83,33 \%)$ manifestam-se pela privação afetiva; pela ausência do papel dos pais e de estruturação da célula familiar; e deficiência na administração das relações interpessoais. Elas nos mostram relações conturbadas, enunciadas inicialmente pelos conflitos e depois pelas crises que refletem maciçamente nas crianças e nos adolescentes. Sendo a família uma instituição social, é dever do Estado definir uma política pública para protegê-la.

No grupo comparativo, as representações sociais da violência doméstica traduzem a ideologia do senso comum, em solicitação de justiça associada ao sentimento de sofrer como características da solidariedade entre os adolescentes. Elas denunciam atitudes de auto moralização, como tentativa de se sanear a violência doméstica.

\section{Considerações finais}

Procuramos destacar neste trabalho, o que os adolescentes pensam, sentem e elaboram sobre o abuso físico na infância e em quais áreas eles ancoraram suas representações sociais.

Após a análise minuciosa desse conjunto de representações sociais, consideramos que os temas-centrais aqui apresentados articulam-se com as disciplinas diretamente ligadas às propostas de prevenção primária e secundária que atendam não só à criança e ao adolescente, após a agressão, mas que haja solução de continuidade e assistência integrada aos equipamentos sociais, às unidades básicas de saúde e aos hospitais e prontos-socorros.

A assistência universalizada aos parentes protege a criança e o adolescente de modelos de identificação inadequados, considerandose que o contingente de agressores, que constitui nossa complexa realidade social está aumentando, devido à nossa diversidade cultural, que tem regras morais diferenciadas e que, devido aos acontecimentos políticos e sociais, propiciam oscilações sócio-econômicas.

Dentre os temas centrais de prevenção, os resultados desta pesquisa revelam, também, que as representações sociais da violência doméstica ou familiar estão associadas indiretamente à ausência de proteção do Estado, que deveria proporcionar mecanismo na luta contra esse arbítrio cotidiano e contra a violência generalizada, na medida em que ela possui ramificações sociais e causa sofrimento a todos os indivíduos, em todos os segmentos da sociedade (Cardoso, 1980).

Tanto na violência privada quanto na violência pública, $20 \%$ dos 90 adolescentes, revelaram o desejo de mudanças sociais capazes de evitar os efeitos de singularidades psicológicas. Eles descreveram ações e desempenhos sociais que precisam de reações políticas em direção às atitudes antiéticas de pessoas que detêm o poder, para prevenir e proteger a sociedade das violências em geral, mas que agem contrariamente: "um dia, um policial mandou eu encostar no muro, deu uma revista geral, pediu dinheiro. Eu falei que não tinha, aí eles me chutaram, me mandaram embora, empurrando..." "Não sei, até hoje, porque os policiais me bateram..." "Apanhei da polícia, com pedaço de madeira e recebi coronhadas".

A vunerabilidade psicossocial, tanto do agressor quanto da vítima, requer, também, a atenção dos profissionais das áreas de saúde mental e educação. Em alguns relatos a psicopatologia parece explicar os comportamentos desviantes, embora, a grosso modo, a violência doméstica se apresente nesta pesquisa como uma construção social, porque os comportamentos agressivos ou muito violentos dos pais contra os filhos parecem munidos de um conjunto de significado social que lhes dão esta referência (Doise \& Papastamou, 1987).

Consideramos que, através do cumprimento do Estatuto da Criança e do Adolescente e de políticas públicas de assistência à família meta prioritária na prevenção deste fenômeno social - seja possível abolir os sentimentos de desesperança, abandono, privação e desproteção, simbolizados pela cronicidade de agressões físicas contra crianças e pelo desenvolvimento de comportamentos anti-sociais e violentos desenvolvidos pelos adolescentes.

Dos 90 adolescentes, $65 \%$ destacaram categorias que norteiam uma proposta interdisciplinar de prevenção primária e secundária, através do desenvolvimento de políticas públicas que propiciem, efetivamente: 1) informação e educação, proteção familiar e social, assistência médica e psicológica às crianças e aos adolescentes vitimados, possibilitando seu desenvolvimento mental e emocional saudáveis; 2) assistência à saúde mental das famílias em sofrimento mental, visando curar as seqüelas psicológicas; 3 ) implantação de programa interdisciplinar direcionado ao atendimen- 
to a alcoolistas, dependentes químicos, desempregados e desajustados sociais, buscando o equilíbrio afetivo, social e cognitivo, integrado ao ambiente familiar; 4) formação e orientação de policiais, quanto à abordagem e condutas direcionadas às crianças e aos adolescentes, no desempenho de seus trabalhos.

\section{Referências}

Aberastury A 1981. Adolescência Normal: um Enfoque Psicanalítico. In Arminda Aberastury \& Maurício Knobel, tradução de Suzana Maria Garagosa Y Ballve, Artes Médicas, Porto Alegre.

Abric JC 1994. Pratiques Sociales et Représentation. PUF, Paris.

Aissami Y, Bonardi C \& Guelfucci B 1990. Représentation sociale et noyau central: problemes de méthode. Ver Intern Psych Soc 3(3): 335-356.

Bardin F 1988. Análise do Conteúdo. Edições 70, Lisboa, $225 \mathrm{pp}$.

Cardoso FH 1980. Violência e Reação. Folha de São Paulo, 22 de junho.

Crami - Centro Regional de Registro e Atenção aos Maus Tratos na Infância 1995. Relatório de Atividades. Campinas, São Paulo.

Davitz L \& Davitz J 1992. Como Viver Quase Feliz com Seu Filho Adolescente. Tradução de Roxana Ramaciotti Mires, Mamtese-Norma, São Paulo, 222 pp.

Doise W \& Papastamou S 1987.Représentation sociales des causes de la delinquance: croyances generales et cas concrets. Deviance et Societé 11(2): 153-162.

Gelles RJ 1973. Child abuse as psychopatology. American Journal of Orthopsychiat 43(4): 610-620.
Haskett ME 1990. Social problem-solving skills of young physically abused children. Child. Psychait. Hum. Dev. 21(2): 109-118.

Jodelet D 1994. Les Représentations Sociales. 4ed., PUF, Paris.

Kovács MJ 1991. Pensando a morte e a formação de profissionais de saúde, p. 79-103. In RMS Cassorla, Da Morte, Papirus, Campinas.

Monteiro MCN 1992. Aspectos Psicossociais de Pais e Responsáveis Agressores de Crianças e Adolescentes Atendidos no Centro Regional de Registro e Atenção aos Maus Tratos na Infância. Dissertação de Mestrado, Faculdade de Ciências Médicas, Universidade Estadual de Campinas, Campinas.

Moscovici S 1976. La Psychanalyse: Son Image et Son Public, 2a ed., PUF, Paris, 504 pp.

Santos HO 1987. Crianças Espancadas. Papirus, Campinas, $132 \mathrm{pp}$.

Veja 1997. Planalto Selvagem: uma Noite de Tédio, Cinco Garotos Melancólicos Tocam Fogo num Índio para se Divertir. Edição 1493, de 30 de abril. 